\title{
Trigeminal neuropathy as the presenting symptom of systemic sclerosis
}

\author{
M. J. BURKE* \\ M.B., M.R.C.P. \\ J. E. CARTY \\ M.B., M.R.C.P.

\begin{abstract}
Department of Rheumatology, Manchester Royal Infirmary, Withington Hospital, Manchester
\end{abstract}

\begin{abstract}
Summary
Three cases of systemic sclerosis in which trigeminal neuropathy was the presenting symptom are described. All 3 patients had progressive diseases and 2 died from its complications.

In each case extensive neurological investigation was undertaken before the disease was recognized and it is suggested that earlier recognition of the systemic sclerosis might obviate the need for this. Trigeminal neuropathy in systemic sclerosis was associated with a poor prognosis in 2 of the patients.
\end{abstract}

\section{Introduction}

Trigeminal sensory neuropathy as a manifestation of systemic sclerosis was first described by Beighton, Cumnel and Corner in 1968. The authors reported a 66-year-old woman who presented with bilateral sensory loss in the second division of the trigeminal nerve. Over a few weeks involvement of all 3 divisions of the nerve on both sides of the face occurred. Concurrently she complained of Raynaud's phenomenon, a polyarthritis, muscle weakness and skin changes.

Three further cases are reported in which trigeminal sensory neuropathy was the presenting feature of systemic sclerosis.

\section{Case reports}

\section{Case 1}

The patient, a 63-year-old woman was well until late 1971 when she noticed numbness of the left side of the face which progressed rapidly to involve the contralateral side and the circumoral area. She also noticed numbness of the tongue.

She was seen in a Neurological Unit in 1973 where investigations including skull X-ray and cerebrospinal fluid examination, were normal. On further questioning she gave a history of Raynaud's phenomenon since childhood and also of stiffness in

\footnotetext{
* Present address: Burnley General Hospital, Casterton Avenue, Burnley, Lancs., BB10 2PQ.
}

the fingers and wrists starting after the onset of facial symptoms.

After the development of dysphagia in March 1974 she was referred to the Rheumatology Unit, Withington Hospital, Manchester. Examination revealed a small, contracted mouth, thickening of the circumoral skin and telangiectasia of the eyelids. The fingers were tapered and showed marked vasospasm without infarction. The skin and subcutaneous tissues were thickened. She was normotensive. Persistent crepitations were heard at both lung bases. There was bilateral loss of pinprick and light touch appreciation over the second and third divisions of the trigeminal nerve. The rest of the nervous system was unremarkable.

Investigations. Haemoglobin $11 \cdot 2 \mathrm{~g} / \mathrm{dl}$; white cell count $3.4 \times 10^{9} / 1$ from normal differential; ESR (Westergren) $105 \mathrm{~mm}$ in 1st hr; blood film showed Rouleaux formation. Serum albumin $3.5 \mathrm{~g} / \mathrm{dl}$; serum globulin $5.0 \mathrm{~g} / \mathrm{dl}$; creatinine clearance normal. Muscle enzymes CPK, SGOT, normal; sheep cell agglutination test (SCAT) positive $>1 / 256$; latexpositive $>1 / 640$; L.E. cells $(\times 3)$ negative; antinuclear factor positive, speckled pattern $(1 / 100)$; $\mathrm{X}$-ray chest, reticular shadowing both lower zones and small left pleural effusion. Barium swallow showed loss of normal oesophageal peristalsis. Carbon monoxide diffusing capacity, $9.7 \mathrm{ml} \mathrm{mm}^{-1}$ $\mathrm{mmHg}^{-1}$ (predicted value for patient, $20.5 \mathrm{ml} \mathrm{mm}^{-1}$ $\left.\mathrm{mmHg}^{-1}\right)$.

After consideration of the clinical findings and investigations a diagnosis of systemic sclerosis was made. Treatment was started with D-penicillamine in a dosage of up to $500 \mathrm{mg} /$ day. This made no difference to her facial symptoms nor to the systemic disease. She died in December 1974 from cardiac failure of rapid onset.

\section{Case 2}

The patient, a 22-year-old man, became aware of altered sensation over the left side of the face. Initially throbbing, this gave way to a sensation of fullness and smoothness in the affected area most 
marked when shaving. One month later he developed Raynaud's phenomenon.

Initial neurological investigations carried out to exclude a suspected cavernous sinus aneurysm included cerebrospinal fluid examination, skull $X$-ray and bilateral carotid angiography; all were normal. The ESR was elevated as was the serum globulin. He was referred to the Rheumatology Clinic where further questioning revealed symptoms of aching of the thighs after climbing stairs and of exertional dyspnoea.

The fingers were cold, mauve in colour and there was soft tissue thickening of the fingers and hands. Limitation of grip was noted. The quadriceps femoris muscles were weak and shortened as were the long extensors of the forearms. He was normotensive and there were no added breath sounds.

There was bilateral loss of pinprick sensation in the following areas: left forehead, over both cheeks and symmetrically below the mouth. The left side of the tongue was anaesthetic.

Investigations. Haemoglobin $11 \cdot 1 \mathrm{~g} / \mathrm{dl}$; white cell count $5.7 \times 10^{6} / 1$ normal differential; ESR (Westergren) $36 \mathrm{~mm}$ in $1 \mathrm{st} \mathrm{hr}$; serum albumin $4.2 \mathrm{~g} / \mathrm{dl}$; serum globulin $4.2 \mathrm{~g} / \mathrm{dl}$; serum SGOT normal; serum LDH normal; serum CPK elevated, 142 u./1 (normal 60); creatinine clearance normal; SCAT and latex, negative; L.E. cells $(\times 3)$ negative; anti-nuclear factor, positive, speckled pattern $(1 / 100)$; anti-DNA antibodies, negative; X-ray chest, normal; X-ray hands, normal; barium swallow and meal, normal; carbon monoxide diffusing capacity, $22.0 \mathrm{ml} \mathrm{mm} \mathrm{mm}^{-1} \mathrm{mmg}^{-1}$ (predicted value for patient, $34.8 \mathrm{ml} \mathrm{mm}^{-1} \mathrm{mmHg}^{-1}$ ). Electromyography suggested a diffuse myositis with polyphasic units. Muscle biopsy from the long extensors of the right forearm showed infiltration of lymphocytes, histiocytes and polymorphonuclear cells. There was evidence of atrophy and regeneration of muscle cells compatible with a diagnosis of myositis.

Treatment with D-penicillamine up to $375 \mathrm{mg} /$ day commenced in late 1974 until thrombocytopenia compelled its withdrawal in May 1976. At his last attendance, December 1977, there had been no amelioration of any of his symptoms. The pulmonary abnormality persists and the Raynaud's attacks are, if anything, more troublesome. The skin changes progressed somewhat and he complains of weakness of the thighs after walking up hills.

\section{Case 3}

The patient, a 36-year-old woman, consulted her dentist in July 1974 after noticing anaesthesia of the inside of her cheeks. She also felt an abnormal sensation on the right cheek most marked when applying make-up. She was seen by a neurologist who found evidence of anaesthesia on the right side of her face in the second and third divisions of the fifth nerve, sensory loss in the mouth and right- $\frac{3}{\infty}$ sided taste loss. Skull X-ray, cerebrospinal fluid $\cong$ examination and computerized tomography of the $\stackrel{c}{\Rightarrow}$ brain revealed no abnormality. On direct ques- $\overrightarrow{\vec{F}}$ tioning she admitted to Raynaud's phenomenon for about one year.

She was given prednisolone $15 \mathrm{mg} / 24 \mathrm{hr}$. This controlled the Raynaud's phenomenon but the drug was stopped in January 1976 at the time of surgery for a perforated duodenal ulcer. By July 1976 the neuropathy involved the second and third divisions of the fifth nerve on the opposite side. She was showing obvious sclerodermatous changes in the hands when she was admitted to the Rheumatism Unit in December 1976. She had prominent facial telangiectasia and keratoconjunctivitis sicca. She was normotensive and the lungs were normal. There were no abnormal neurological signs other than those previously noted nor was there clinical evidence of muscle weakness.

Investigations. Haemoglobin $11.9 \mathrm{~g} / \mathrm{dl}$; white cell count $8.6 \times 10^{9} / 1$, normal differential; ESR (Westergren) $49 \mathrm{~mm}$ in $1 \mathrm{st} \mathrm{hr}$; serum albumin $3.2 \mathrm{~g} / \mathrm{dl}$; serum globulin $4 \cdot 1 \mathrm{~g} / \mathrm{dl}$; creatinine clearance normal. Muscle enzymes CPK, SGOT, were normal but biopsy revealed non-specific inflamb matory change in the muscle with chronic inflan matory cells around blood vessels; SCAT positive. $>1 / 256$; latex positive $>1 / 640$; L.E. cell prepara tion $(\times 3)$ negative; anti-nuclear factor, positive, speckled pattern at $1 / 100$ dilution; anti-DNA antibodies, negative. Extractable nuclear antigens (ENA), negative. X-ray chest, normal; X-ray hands, juxta-articular osteoporosis. Electromyography showed generalized myositis with short polyphasic units. ECG, normal; barium swallow, normal oesophagus; barium meal, scarred duodenum; carbon monoxide diffusing capacity, $26.0 \mathrm{ml} \mathrm{mm}^{-1}$ $\mathrm{mmHg}^{-1}$ (predicted normal value).

She was started on prednisolone $15 \mathrm{mg} /$ day in January 1976 but this led to the reappearance of ulcer symptoms and an attack of pancreatitis. The steroid was again stopped but was restarted in June 1977 when joint pain and stiffness became troublesome.

In August 1977 she was admitted in left ventricular failure and was now found to be hypertensive (BP $170 / 110 \mathrm{mmHg}$ ) and in mild renal failure (creatinine clearance, $48 \mathrm{ml} / \mathrm{min}$ ). Electrocardiography showed biventricular hypertrophy and echocardiography was compatible with a diagnosis of cardiomyopathy, the left ventricle contracting poorly throughout.

The patient repeatedly relapsed into cardiac failure throughout the rest of 1977 despite treatment with digoxin and high doses of diuretics. In December 1977 she passed into terminal congestive cardiac 
failure aggravated by increasing renal failure and recurrent peripheral thromboembolism.

\section{Discussion}

Trigeminal neuropathy has been described in systemic sclerosis (Beighton et al., 1968; Ashworth and Tait, 1971), disseminated lypus erythematous (Ashworth and Tait, 1971) and mixed connective tissue disease (Sharp, 1975). In the latter disease, neurological system involvement occurs in $10 \%$ of cases and trigeminal neuropathy is said to be the commonest neurological disorder (Sharp, 1975). These 3 patients were diagnosed as having systemic sclerosis on their clinical presentation and abnormal laboratory findings. The failure to find ENA in the patient in whom it was sought suggests that she did not have mixed connective tissue disease (Sharp et al., 1972).

In the first case of trigeminal sensory neuropathy in systemic sclerosis described, trigeminal neuropathy was the presenting symptom. Ashworth and Tait (1971) added 5 further cases to the literature and it is noteworthy that fifth nerve involvement occurred within 3 years of the appearance of the disease. Evolution of the neuropathy was rapid and complete within weeks as it was in our patients with the exception of the third. The neuropathy in the patients reported here and in those previously described (Beighton et al., 1968, Ashworth and Tait, 1971) was a sensory neuropathy presumably on the basis of a vascular lesion within or around the gasserian ganglion (Spillane, 1975).

Trigeminal neuropathy can occur without evidence of other disease. Trophic changes may occur in the skin of the nose in the affected areas of such patients (Spillane, 1975). In other diseases causing trigeminal neuropathy the natural history is somewhat different. In sarcoid, granulomatous lesions and neoplasm the onset is said to be insidious; progression of the lesion is slow and all 3 divisions of the nerve are affected.

In these 3 patients the onset of the neuropathy was in accord with previous accounts of such occurrences and led to extensive neurological investigation before the diagnosis was established.

All 3 patients have or had active systemic sclerosis. Two had significant pulmonary abnormalities and 2 marked myositis. All had troublesome Raynaud's phenomenon. Certainly one if not 2 died of the cardiac complications of the disease. On these grounds it is thought that the occurrence of trigeminal neuropathy implies a poorer prognosis in systemic sclerosis than an earlier report suggests (Ashworth and Tait, 1971). It is also suggested that the symptoms of trigeminal neuropathy may antedate the onset of systemic sclerosis, but that other signs and symptoms of systemic sclerosis usually become obvious at or shortly after the appearance of the neuropathy. This applies particularly to Raynaud's phenomenon. An awareness of this presentation of systemic sclerosis and the history of its progression might avoid invasive neurological investigation.

\section{Acknowledgments}

We wish to thank Dr J. Sharp and Dr P. J. L. Holt for permission to report these cases under their care and for their encouragement and advice in preparing this paper. We also thank Miss Lesley Scoltock for kindly typing the manuscript.

\section{References}

Ashworth, B. \& TAIT, G.B.W. (1971) Trigeminal neuropathy in connective tissue disease. Neurology, 21, 609.

Beighton, P., Gumpel, J.M. \& Cornes, N.G.M. (1968) Prodromal sensory neuropathy in progressive systemic sclerosis. Annals of the Rheumatic Diseases, 27, 367.

SharP, G.C., IRWIN, W.S., TAN, E.M., Gould, G.R. \& Holman, H.R. (1972) Mixed connective tissue, an apparently distinct rheumatic disease with a specific antibody to extractable nuclear antigen (E.N.A.) American Journal of Medicine, 52, 148.

SharP, G.C. (1975) Mixed connective tissue disease. Overlap syndromes. Systemic lupus erythematosus. In: Clinics in Rheumatic Diseases, 1, 561.

Spillane, J.D. (1975) An Atlas of Clinical Neurology, 2nd edn, p. 91. Oxford Medical Publications, New York \& London. 